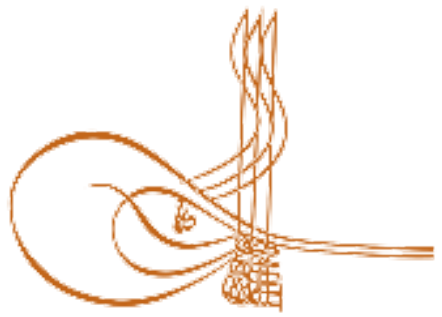

www.turkishstudies.net/education
Turkish Studies - Educational Sciences

eISSN: $2667-5609$

Research Article / Araştırma Makalesi

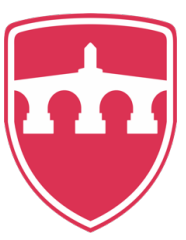

INTERNATIONAL

BALKAN

UNIVERSITY

Sponsored by IBU

\title{
Yabancı Dil Dersinde Katılımın Ölçümü: Yabancı Dil Dersi Katılım Ölçeği*
}

Measuring Engagement in EFL Context: Language Learner Engagement Scale

\author{
Eylem Oruç ${ }^{* *}$ - Cavide Demirci ${ }^{* * *}$
}

\begin{abstract}
Student engagement is considered to be an important constract in examining dynamics of foreign language classroom. The studies on language teaching have mostly focused on behavioral dimension of engagement. Based on a more comprehensive understanding of student engagement and language teaching theory and practises, a scale was developed to measure language learner engagement in foreign language classroom. 198 English preparatory class students participated in the study in Turkey. The steps followed in the study were generating items, content adequacy assessment, administrating questionnaire, item discrimination analysis, factor analysis and internal consistency assessment. The language learner engagement scale was developed as a 5-point likert type scale and it included 18 items in 3 factors: cognitive, affective and social engagement. EFA showed that the total variance explained was $49.24 \%$. Also, internal consistency assessment revealed that the Cronbach alpha reliability coefficient is $=.86$ and (cognitive engagement $=.76$, affective engagement $=.83$, social engagement $=.73$ ). This study showed that the Language Learner Engagement Scale is a valid and reliable measure that can be used to investigate language learner engagement. The factors of the Language Learner Engagement Scale (cognitive engagement, affective engagement and social engagement) were labelled based on the concept of "engagement with language" suggested by Svalberg (2009:
\end{abstract} 247).

Structured Abstract: Demographic, economic and technological changes in the world has led the universities to become global institutions. Therefore, they need to raise more successful and productive citizens than before. The concept of student engagement (Astin, 1984: 299), which is defined as the physical and psychological energy used by students for their academic lives and learning, has attracted attention to develop learning and teaching processes in higher education in recent years. Student engagement has a significant impact on student performance by providing an important basis for social, emotional and cognitive development in university life

\footnotetext{
* Bu çalışma, Eskişehir Osmangazi Üniversitesi Eğitim Bilimleri Enstitüsü’nde Prof. Dr. Cavide DEMİRCI danışmanlığında Eylem Oruç tarafından hazırlanan ve Bilimsel Araştırma Projeleri Komisyonu tarafından 2017-1756 nolu proje olarak desteklenen doktora tezinden üretilmiştir. Ayrıca, ICONSR 2018'de özet bildiri olarak sunulmuştur.

** Öğr. Gör. Dr., Bilecik Şeyh Edebali Üniversitesi, Yabancı Diller Yüksekokulu, Yabancı Diller Bölümü Dr., Bilecik Seyh Edebali University, School of Foreign Languages, Department of Foreign Languages ORCID 0000-0003-2707-8986

eylem.unal@bilecik.edu.tr

*** Prof. Dr., Eskişehir Osmangazi Üniversitesi, Eğitim Fakültesi, Eğitim Programları ve Öğretim

Prof. Dr., Eskişehir Osmangazi University, Faculty of Education, Curriculum and Intruction

ORCID 0000-0003-4789-4286

Cite as/ Atıf: Oruç, E. \& Demirci, C. (2020). Yabancı dil dersinde katılımın ölçümü: yabancı dil dersi katılım ölçeği,

Turkish Studies - Education, 15(2), 1113-1126. https://dx.doi.org/10.29228/TurkishStudies.40025

Received/Geliş: 05 December/Aralık 2019

Checked by plagiarism software

Accepted/Kabul: 25 April/Nisan 2020

Published/Yayın: 30 April/Nisan 2020

Copyright (C INTAC LTD, Turkey CC BY-NC 4.0
} 
(Asghar, 2014, p. 249). In this sense, student engagement is an important concept to increase students' academic achievement and motivation and to improve learning and teaching processes.

Since foreign language teaching needs to be more effective in our age, different dynamics in the foreign teaching process should be examined. When examining the variables of the foreign language classroom, Oga-Baldwin and Nakata (2017, p. 151) state that studies in which student engagement is disregarded are insufficient in explaining the dynamics of the classroom. The concept of engagement in foreign language teaching has been elaborated with different perspectives and it has been theoretically defined in a limited number of studies. In this study, the concept of engagement is examined in the context of foreign language teaching theories and practices and it is aimed to develop a scale relevant to the nature of the foreign language course.

\section{Literature Review}

The concept of engagement in foreign language classroom has been defined operationally in a small number of studies and has been focused on its behavioral aspect. According to Ellis (2010: 342), engagement in language learning process refers to learners' responses to teacher feedbacks. However, it can be considered that responses to teacher feedback are only part of engagement in a foreign language course. Philip and Duchesne (2016: 70) argue that engagement varies based on classroom context, and this concept should be conceptualized by considering the learning environment, tasks and students. Engagement should be defined in terms of language teaching theory and practice.

An operational definition of engagement in the language classroom was suggested by Svalberg (2009). Language learner engagement is a concept which includes certain cognitive situations, affective tendencies and social attitudes as well as actions and behaviors in classroom evironment in which the learner acts as a subject and language is as an object or communication tool (Svalberg, 2009: 245). It consists of cognitive, affective and social dimensions. Cognitive engagement requires the learner to be alert, focus his attention and construct knowledge. Autonomy is also considered as a part of cognitive engagement. Affective engagement on the other hand, refers to positive orientation towards language and willingness to interact with language. Lastly, social participation means behavioral readiness to interact, intiating and maintaining interaction.

Svalberg (2009: 248) states that language learner engagement is a cyclical process that enables learners to develop language awareness. Cognitive, affective and social dimensions interact in this cycle. Students' fatigue levels, health, emotional states, and task designs may affect their cognitive engagement. In addition, affective engagement can be influenced by task content, personality traits, and cognitive-social factors such as self-perception and group dynamics. Finally, social engagement can be affected by friendships, power dynamics and group values (Svalberg, 2017: 4). Therefore, as well as cognitive, affective and social factors affect each other, they appear as interdependent dimensions. In order to understand language learner engagement, it is necessary to understand how these factors relate to and how they interact with each other.

\section{Method}

The study aims to develop a scale to measure language learner engagement in foreign language classroom. It was conducted during the spring semester of 2017-2018 academic year. The participants were 198 English preparatory class students at a university in Marmara Region in Turkey. The scale development process consisted of item generation, content adequacy assessment, questionnaire administration, item discrimination, factor analysis and internal consistency assessment.

Item generation: Literature review was conducted to determine the theoretical framework of the concept. Language learner engagement which was defined by Svalberg (2009: 244) was adopted to create sample items. The key characteristics of language learner engagement in each dimension (social, affective and cognitive) were used to generate 44 items.

Content Adequacy Assessment: Lawshe's CVR method was used to test the content adequacy of the items. 8 items were excluded from the scale.

Questionnaire Administration: The 5-point likert scale with 36 items was applied to 195 people (93 women and 102 men) in the Foreign Language Department of a university in Marmara Region in Turkey.

Item discrimination: After the questionnaire administration, item total correlation was analysed and 8 items were excluded from the scale. 
Factor analysis: Explaratory factor analysis was conducted using varimax rotation method to identify the factors of the scale. As a result of the analysis, 10 factors loaded below . 30 on more than one factor were omitted. 18 items were loaded on 3 factors and the factors explained $49.2 \%$ of the total variance. The first factor explained $18.3 \%$ of the total variance, the second factor explained $17 \%$, and the third factor explained $13.9 \%$. Factor loads of the items ranged from 372 to 808 . In addition, the eigenvalues of the factors vary between 1.329 and 5.898. In addition, These results show that the scale has sufficient validity.

Internal consistency assessment: The reliability of the scale was examined by internal consistency method. The Cronbach Alpha coefficients of the scale were calculated. Cronbach Alpha internal consistency coefficients ranged between .73 and .83 for the factors, whereas it was .86 for the overall scale. In addition, significant and positive relationships between the factors of the scale support that the scale is a reliable scale. These results show that the scale has a sufficient reliability.

\section{Conclusion}

Engagement is considered as an important variable in examining the dynamics of foreign language teaching in the classroom (Oga-Baldwin and Nakata, 2017: 151). Engagement in foreign language classroom has been defined operationally in a small number of studies. In this study, the concept of engagement is examined in the context of foreign language teaching theories and practices and it is aimed to develop a scale relevant to the nature of the foreign language course.

In this study, the theoretical framework and language learning processes are emphasized in conceptualizing engagement with it aspects of cognitive, social and affective engagement. The key characteristics of language learner engagement by Svalberg (2009: 247) were used to label the three factors after exploratory factor analysis. Therefore, they were labelled as affective engagement, cognitive engagement and social engagement. It can be argued that Language Learner Engagement Scale is a valid and reliable instrument to measure learner engagement in language classroom.

Keywords: Foreign Language Teaching, Engagement In EFL Classroom, Affective Engagement, Social Engagement, Cognitive Engagement

Öz: Katılım, sınıf ortamında yabancı dil öğretiminin dinamiklerini araştırmada önemli bir değişken olarak karşımıza çıkmaktadır (Oga-Baldwin ve Nakata, (2017: 151). Yabancı dil öğretimiyle ilgili literatürde katılım kavramının farklı boyutları ele alınmış olmasına rağmen bu kavram ampirik çalışmalarda genellikle tek bir boyutta ele alınmıştır. Katılım kavramını yabancı dil dersi bağlamında ele alan bu araştırmada, katılımın bilişsel, sosyal ve duyuşsal yönüne vurgu yapılarak dil edinimi teorik çerçevesi ve dil öğrenme hedef-süreçleri temel alınarak yabancı dil dersinde katılım ölçeğinin geliştirilmesi amaçlanmaktadır. Araştırma, 2017-2018 yılı bahar döneminde Marmara Bölgesindeki bir üniversitede 198 İngilizce hazırlık sınıfı öğrencilerin üzerinde gerçekleştirilmiştir. Ölçek geliştirme süreci, madde havuzu oluşturma, kapsam geçerliğinin değerlendirilmesi, pilot uygulama, madde ayırt-ediciliğgin belirlenmesi, faktör analizi ve iç tutarlılık analizinden oluşmaktadır. Araştırma sonucunda 5'li likert yapıda 18 maddeli ve bilişsel, duyuşsal ve sosyal katılım olmak üzere üç boyuttan oluşan bir ölçek elde edilmiştir. Açımlayıcı faktör analizi sonuçlarına göre açıklanan varyans $\% 49.24$ olarak belirlenmiştir. İç tutarlılık analizi sonuçlarına göre ölç̧eğin genel güvenirlik katsayısı =.86, bilişsel katılım $=.76$, duyuşsal katılım $=.83$, sosyal katılım $=.73$ olarak belirlenmiştir. Yabancı Dil Dersinde Katılım Ölçeği’nin yabancı dil dersinde öğrenci katılımının ölçülmesinde geçerli ve güvenilir bir ölçek olduğu belirlenmiş̧tir. Yabancı Dil Dersi Katılım Ölçeği’nin boyutlarının duyuşsal katılım, bilişsel katılım ve sosyal katılım olarak isimlendirilmesinde Svalberg' in (2009: 247) yabancı dil dersinde katılım kavramı için öne attı̆̆ boyutlar temel alınmıştır.

Anahtar Kelimeler: Yabancı Dil Öğretimi, Yabancı Dil Dersinde Katılım, Duyuşsal Katılım, Sosyal Katıılım, Bilişsel Katılım

\section{Giriş}

Dünyadaki demografik, ekonomik ve teknolojik değişimler sonucu küresel kurumlar haline gelen üniversiteler, başarılı ve üretken vatandaşlar yetiştirmeye eskisinden daha fazla ihtiyaç 
duymaktadır. Öğrencilerin akademik yaşantıları ve öğrenmeleri için kullandığı fiziksel ve psikolojik enerji olarak tanımlanan öğrenci katılımı kavramı (Astin, 1984: 299) son yıllarda yükseköğretimde öğrenme ve öğretme süreçlerinin geliştirilmesi noktasında dikkatleri üzerine çekmektedir. Öğrenci katılımı, öğrencilerin üniversite yaşamında sosyal, duygusal ve bilişsel gelişim için önemli bir zemin hazırlayarak öğrenci performansını büyük çapta etkilemektedir (Asghar, 2014: 249). Bu anlamda, öğrenci katılımı, öğrencilerin akademik başarıları ve motivasyonları artırmak ve öğrenme öğretme süreçlerinin geliştirilmesi için önemli bir faktör olarak değerlendirilmektedir.

Çağın gereksinimleri yabancı dil öğretim sürecinin daha verimli bir süreç haline getirilmesini zorunlu kılmaktadır. Bu durum, birçok değişkeni içinde barındıran yabancı öğretim sürecindeki farklı dinamiklerin incelenmesi gerektiğini göstermektedir. Sınıf ortamında yabancı dil öğretim sürecinin değişkenlerini incelerken yabancı dil dersinde katılım kavramını dikkate almayan çalışmaların bu kavramları açıklamada yetersiz kalacağı ifade edilmektedir (Oga-Baldwin ve Nakata, 2017: 151). Yabancı dil öğretimiyle ilgili literatürde katılım kavramının farklı çalışmalarda farklı boyutlarıyla ele alınmış olmasına rağmen bütüncül olarak çok az sayıdaki çalışmada teorik olarak tanımlanmış ya da amprik çalışmalarda genellikle tek bir boyutuna odaklanılmıştır. Svalberg'e (2017: 1) göre yabancı dil dersinde katılımla ilgili şimdiye kadar yapılan çalışmalar katılımın bilişsel yönüne odaklanırken yeni çalışmalar sosyal ve duyuşsal faktörlerini konu almaktadır. Philip ve Duchesne (2016: 70) katılımın bağlama göre farklılık göstereceğini ve bu kavramın öğrenme ortamı, görevler ve öğrenciler göz önünde bulundurarak kavramsallaştırılması gerektiğini savunmaktadır. Özellikle dil edinimi teorik çerçevesini temel alan ve dil öğrenme hedef-süreçlerine özgü bir katılım tanımı yapılmalıdır. Bu araştırma katılım kavramını yabancı dil öğretimi teori ve uygulamaları çerçevesinde ele alarak yabancı dil dersi bağlamında değerlendirmiştir.

\section{Öğrenci Katılımı}

Öğrencilerin aktif bir şekilde öğrenme-öğretme sürecine katılımlarını sağlama düşüncesi Dewey'in 1899 yılında yapmış olduğu çalışmalara dayanmaktadır (Finn ve Cox, 1992: 141). Literatürde kavrama ilişkin ilginin 80'lerde Astin'in (1984) çalışmalarıyla tekrar başladığı ve esasen 90'ların ortasından itibaren birçok araştırmanın konusu haline geldiği görülmektedir. Astin öğrenci katılımını (student involvement) öğrencilerin akademik yaşantıları için sarf ettikleri fiziksel ve psikolojik enerji düzeyi olarak tanımlamaktadır (Astin, 1999: 518).

Öğrenci katılımıyla ilgili genel olarak iki temel yaklaşım bulunmaktadır (Fredericks vd., 2004: 60). Bunlardan ilki katılım kavramını genel olarak öğrencinin okulla olan ilişkisi ve okuldaki katılımı olarak ele almaktadır. Buna göre, öğrencinin diğer kişiler, etkinlikler, amaçlar, değerler ve mekanı da içinde bulunduran ilişkisi katılıma karşılık gelmektedir (Skinner, Kinderman, and Furrer, 2009: 494). Anderson, Christenson, Sinclair ve Lehr'e (2004: 96) göre öğrenci katılımı; derse gelme, dersi dinleme, söz alma gibi pozitif davranışlarla öğrencilerin okula bağlılıkları ve kendilerini psikolojik olarak okul çevresinin bir parçası olarak hissetmeleridir. Kuh (2009: 684) ise öğrenci katılımını, öğrencilerin amaçları doğrultusunda eğitim faaliyetlerine harcadıkları zaman ve çaba olarak ifade etmektedir. Bu anlamda, katılım kavramı akademik katılım, öğretim üyeleriyle iletişim, ders dış1 etkinliklere katılma, arkadaşlarla etkileşim gibi boyutları içermektedir.

İkinci yaklaşım ise öğrenci katılımını sınıf içindeki yaşantılar bakımından değerlendirmektedir. Bu sebeple, öğrencilerin sınıf ortamında nasıl düşündüklerini, nasıl hareket ettiklerini ve nasıl hissettiklerini tasvir eden çok yönlü bir kavram olarak tanımlanmıştır (Fredericks vd., 2004: 60). Newmann, Wehlage ve Lamborn (1992: 11) katılımı öğrencilerin bilgi ve becerileri öğrenmek ve anlamak için yaptıkları psikolojik yatırımlar ve bu süreçteki çabalar olarak tanımlamaktadır. Bu tanım katılımı, öğrenme çabası ve bilişsel bir süreç olarak ele aldığından gözlemlenemeyen özelliklere işaret etmektedir. Aynı şekilde Marks (2000: 154) katılımı psikolojik bir süreç olarak değerlendirmekte ve öğrencilerin öğrenme sırasındaki dikkat, ilgi ve çabaları olarak tanımlamaktadır. 


\section{Yabancı Dil Dersinde Katılım}

Sınıf ortamında yabancı dil öğretiminin dinamiklerini incelerken katılım kavramı önemli bir değişken olarak karşımıza çıkmaktadır (Oga-Baldwin ve Nakata, 2017: 151). Dil öğretiminde katılım kavramı daha çok görev (task) olarak ele alınmıştır (Philip ve Duchesne, 2016: 51). Görev, öğrencilerin kendi kaynaklarını bir araya getirmelerini gerektiren anlam odaklı etkinlikler olarak ifade edilmektedir (Ellis, 2009: 223). Ellis'e (2010: 342) göre katılım, ikinci dil öğrenme sürecinde öğrenenlerin geribildirimlere olan karşılıklarını ifade etmektedir. Ancak, geribildirimlere verilen yanıtların yabancı dil dersinde katılımın sadece bir parçası olduğu değerlendirilebilir. Bu tanımlar katılım kavramını oldukça sınırladığı görülmektedir. Dil öğretimi sürecinde katılım kavramına ait etkili bir tanımın Svalberg (2009) tarafından yapıldığ görülmektedir. Bilişsel, duyuşsal ve sosyal boyutlardan oluşan katılım, dil öğretim sürecinde öğrenenin özne, dilin ise nesne veya iletişim arac1 olarak rol aldığı, eylemler ve davranışlar kadar belirli bilişsel durumları, duyuşsal eğilimleri ve sosyal tutumları da içerisinde barındıran bir kavramdır (Svalberg, 2009: 245). Svalberg (2009: 246) yabancı dil dersinde katılımı sosyal, bilişsel ve duyuşsal olarak üç boyuta ayırmaktadır.

\section{Bilişsel katılım}

Bilişsel katılım öğrenenin uyanık olmasını, dikkatini odaklamasını ve bilgiyi yapılandırmasını öngörmektedir. Ayrıca, öğrenenin yansıtma yapması problem çözmesi de bilişsel olarak katılım sağladığını göstermektedir (Svalberg, 2009: 246). Fredericks vd.'ye (2004: 63) göre bilişsel katılım, öğrencilerin öğrenmeye harcadıkları zamanla birlikte öğrenme stratejisini ve süreçlerini kullanma isteklerini ifade etmektedir. Benzer șekilde, Reeve (2013: 579) bilișsel katılımı öğrencilerin stratejik olarak nasıl öğrendikleri, Philp ve Duchesne (2016: 51) görevleri tamamlamak için gösterdikleri zihinsel çabanın nasıl gerçekleştiği olarak ele almaktadırlar. Bilişsel katılım, özdüzenleme, öğrenmeye değer verme, kişisel hedefler ve özerklik gibi, daha az gözlemlenebilir ve içsel olan göstergelere sahiptir (Appleton vd., 2006: 429). Baralt, Gurzynski-Weiss ve Kim (2016: 222) yabancı dil öğretiminde bilişsel katılımı dil yapılarını fark etme ve bu yapılar üzerine düşünme olarak tanımlamaktadır.

\section{Duyuşsal katılım}

Duyuşsal katılım motivasyonla yakından ilişkili olup öğrenenlerin katılımlarının duyuşsal yönünü ifade etmektedir. Olumlu ya da olumsuz duygular öğrenme çabasını ve stratejisini etkilemektedir (Philip ve Duchesne, 2016: 58). Fredericks vd. (2004: 63) duyuşsal katılımı, öğrencilerin arkadaşlarına, öğretmenlerine ve öğrencilerin okula olan aidiyetlerine karşı duyuşsal tepkileri olarak tanımlamaktadır. Reeve (2013: 579) öğrencilerin duyuşsal olarak katılmaları için etkinlikler sırasında olumlu duygular içinde olmaları ve kaygı gibi olumsuz düşüncelerden uzak olmaları gerektiğini belirtmektedir. Daha geniş bir açıdan ele alınan yönüyle duyuşsal katılım, öğrenenlerin derse karşı tutumları, etkileşimde bulunmaya isteklilik, amaçlılık ve özerkliklerini içermektedir (Baralt vd., 2016: 222; Svalberg, 2009: 246).

\section{Sosyal katılım}

Yabancı dil öğretiminde sosyal katılım, sosyal etkileşimin dili pratik yapmayı sağlaması noktasında önemli bir yere sahiptir. Öğrenci katılımının bu boyutu öğrenenlerin sınıf içi etkinlikler sırasında muhataplarıyla ne kadar iletişim kurduğuyla ilgilidir (Philip ve Duchesne, 2016: 51). Sosyal katılım Baralt vd. (2016: 229) tarafından etkileşim, destek, arkadaşlık, güven ve dahil olma kavramlarıyla tanımlanmaktadır. Akranlarıyla sosyal ilişkiler kuran öğrenenlerin katılım düzeylerinin daha yüksek olduğunu belirtilmektedir. Svalberg'e (2009: 246) göre sosyal katılım iletişim kurmak için davranışsal hazır olmayı, etkileşimde bulunmayı ve girişimci olmayı gerektirmektedir.

Yabancı dil dersinde katılımı anlamak için bu boyutların birbirleriyle nasıl ilişkili olduğunu ve birbirleriyle nasıl etkileştiğini anlamak gerekmektedir. Bilişsel, duyuşsal ve sosyal katılım 
boyutları birbirinden etkilenmektedir. Grup etkinliklerinde öğrencilerin duydukları heyecan ve coşku (sosyal ve duygusal katılım) öğrencilerin bilişsel katılımlarını etkilemektedir. Akran desteği de aynı şekilde hem sosyal hem de bilişsel katılımı göstermektedir (Stroud, 2017: 122). Öğrencilerin, yorgunluk düzeyleri, genel sağlik seviyeleri, duygusal durumları ve öğrenciler için oluşturulan sınıf içi görev tasarımı bilişsel olarak katılımlarını etkileyebilir. Ayrıca, duyuşsal dile katılım görevin konusundan, kişilik özelliklerinden, öz-algı ve grup dinamikleri gibi bilişsel ve sosyal faktörlerden etkilenebilir. Son olarak sosyal katılım ise arkadaşlıklardan, gruptaki güç dinamiklerinden ve değerlerden etkilenebilir (Svalberg, 2017: 4). Böylece katılımın çok boyutlu ve birbirine bağımlı boyutlardan oluşan bir karaktere sahip olması boyutlarının tümüne odaklanılması gerektiğini göstermektedir (Philip ve Duchesne, 2016: 63). Bu katılım türlerinin birbirinden kesin bir şekilde ayrımı ve ayrı bir şekilde analizinden ziyade katılımı bütün olarak ölçmeyi tercih etmek gerekmektedir (Stroud, 2017: 122). Bu çalışmada katılım kavramı yabancı dil öğretimi teori ve uygulamaları bağlamında incelenerek yabancı dil dersinin doğasına uygun bir ölçme aracı geliştirilmesi amaçlanmıştır.

\section{Yöntem}

Öğrenci katılımını ölçmek üzere geliştirilen ya da uyarlanan ölçme araçlarının farklı örneklemler üzerinde ve farklı teorik açılardan ele alındığ görülmektedir (Appleton vd., 2006; Eren, 2013; Ery1lmaz, 2014; Fredricks ve McColskey, 2012; Günüç ve Kuzu, 2015; Gürer, 2013; Güvenç, 2015; Hidıroğlu, 2014; Handelsman vd., 2005; Reeve, 2013; Reeve \& Tseng, 2011). Bu ölçekler, öğrencilerin derslerdeki genel katılımını ya da okula olan bağlılıklarını ölçmek amacıyla geliştirilmiş ya da uyarlanmış olduğundan İngilizce dersi bağlamına uygun olmadığı gözlemlenmiştir. Bu çalışmada İngilizce dersinde öğrenci katılımının incelenmesi amaçlandığından İngilizce dersinde ögrenci katılımının belirlenmesinde kullanılabilecek geçerli ve güvenilir bir ölçme aracına ihtiyaç duyulmaktadır. Bu amaçla, İngilizce hazırlık sınıflarında öğrenci katılımının ölçülmesi amacıyla Yabanc1 Dil Dersi Katılım Ölçeği geliştirilmiştir.

\section{İşlem}

Yabancı Dil Dersi Katılım Ölçeği’nin geliştirilmesinde, teorik yapının oluşturulması, madde havuzunun oluşturulması, kapsam geçerliği, puanlandırma ve uygulama aşamaları takip edilmiştir.

\section{- Teorik Yapının Oluşturulması}

İngilizce Dersi Katılım Ölçeğinin geliştirilmesi için gereken teorik yapının belirlenmesi amacıyla yapılan literatür taramasında Svalberg (2009: 244) tarafindan öne atılan ve dil öğrenme sürecinde öğrenci katılımını ifade eden yabancı dil dersinde katılım (language learner engagement) kavramının benimsenmesine karar verilmiştir.

- Madde Havuzunun Oluşturulması

Teorik altyapıdan yararlanarak ilk toplamda 44 madde belirlenmiştir. Maddelerin yazımında Svalberg'in (2009: 244) öne sürdüğü yabancı dil katılım kavramına ait bilişsel, duyuşsal ve sosyal alt boyutlarına karşılık gelen kriterlerden yararlanılmıştır. Tablo 1'de yabancı dil dersinde katılımıyla ilgili kriterler yer almaktadir. 
Tablo 1: Yabanc1 Dil Dersi Katılım Kriterleri

\begin{tabular}{|c|c|c|}
\hline Bilișsel Katılım & Duyuşsal Katılım & Sosyal Katılım \\
\hline $\begin{array}{l}\text { Dikkat düzeyi } \\
\text { Öğrenci enerjik ya da pasif görünüyor mu? } \\
\text { Dil/etkileşim ögelerini fark ediyor } \\
\text { görünüyor mu? }\end{array}$ & $\begin{array}{l}\text { İsteklilik } \\
\text { Öğrenci kendini geri } \\
\text { planda mı tutuyor? } \\
\text { Katılmaya istekli mi? }\end{array}$ & $\begin{array}{l}\text { Etkileșim düzeyi } \\
\text { Öğrenci öğrenmek için } \\
\text { etkileşimde bulunuyor mu? }\end{array}$ \\
\hline $\begin{array}{l}\text { Odaklanma düzeyi } \\
\text { Öğrenci dile odaklanabiliyor mu? } \\
\text { Öğrenci kendini derse veriyor mu? }\end{array}$ & $\begin{array}{l}\text { Amaçlılık düzeyi } \\
\text { Öğrenci herhangi bir yere } \\
\text { ulaşmayı amaçlıor mu? } \\
\text { Yoksa yerinde mi sayıyor? }\end{array}$ & $\begin{array}{l}\text { Akran desteği düzeyi } \\
\text { Öğrenciler birbirleriyle } \\
\text { uzlaşıyor mu? } \\
\text { Birbirlerine öğrenmeleri için } \\
\text { destek veriyorlar mı? }\end{array}$ \\
\hline $\begin{array}{l}\text { Yansıtma / Eleștirel/Analitik Düșünme } \\
\text { Düzeyi } \\
\text { Öğrenci tümevarımsal akıl yürüyor mu? } \\
\text { Ezber mi yapıyor? } \\
\text { Öğrenci farkediyor ve yansıtma yapıyor ya } \\
\text { da temel tepkiler mi veriyor? } \\
\text { Öğrenci karşılaştırma yapıyor mu? Sorular } \\
\text { soruyor mu? Sonuç çıkarıyor mu? }\end{array}$ & $\begin{array}{l}\text { Özerklik düzeyi } \\
\text { Öğrencilerin davranışları } \\
\text { öğretmenden bağımsız mı? }\end{array}$ & $\begin{array}{l}\text { Liderlik düzeyi } \\
\text { Öğrencilerin etkileşimleri } \\
\text { reaktif mi yoksa proaktif mi? }\end{array}$ \\
\hline
\end{tabular}

Svalberg, A. M. (2009) Engagement with language: interrogating a construct, Language Awareness, 18:34, 242-258. s. 246-247.

Bu kriterler, bilişsel alt boyut için dikkat ve odaklanma düzeyiyle bilgiyi özümseme (yansıtma, eleştirel düşünme, analitik düşünme); duyuşsal alt boyut için dile karşı olumlu tutum, amaçl1lık, isteklilik/seçim ve özerklik; sosyal alt boyut için etkileşim, akran desteği düzeyi ve liderlik düzeyi başlıklarında toplanmıştır.

\section{- Kapsam geçerliği}

Madde havuzunun kapsam geçerliği için Lawshe'nin Content Validity Ratio yönteminden yararlanılmıştır. Ölçek maddelerinin değerlendirilmesi amacıyla 'ölçekten çıkarılmalı', 'geliştirilmeli' ve 'düzeltme önerisi' seçeneklerinden oluşan bir değerlendirme formu 7 uzmanın görüşüne sunulmuştur. Bu uzmanlar seçilirken doktora yapmış olmak, yabancı dil eğitimi konusunda çalışmak ve ölçek geliştirme konusunda çalışmalar yapmış olmak gibi kriterler belirlenmiştir. Uzmanların görüşleri doğrultusunda 8 madde taslak ölçekten çıkarılmış ve maddeler üzerinde gerekli düzeltmeler yapılarak taslak ölçeğe (36 madde) son şekli verilmiştir. Daha sonra maddeler 2 Türk Dili uzmanı tarafindan incelenmiştir.

\section{- Puanlandirma}

Öğrencilerin yabancı dil katılımlarını ölçmek amacıyla hazırlanan taslak ölçek 5'li likert yapısına sahiptir. Cevaplar "1", "Kesinlikle katılmıyorum.”; "2", "Katılmıyorum."; "3", "Ne katıliyorum, ne katılmıyorum."; "4", "Katılıyorum." Ve "5", "Kesinlikle katılıyorum." şeklinde düzenlenmiştir. Ölçekten elde edilen puanların en düşüğü ' 1.00 ' ve en yükseği ' 5.00 ' olacak şekildedir. Ölçekten alınan puanlara karşılık gelen düzeyler;

$1.00-1.80=$ Çok düşük düzeyde,

$1.81-2.60=$ Düşük düzeyde,

$2.61-3.40=$ Orta düzeyde,

$3.41-4.20=$ İyi düzeyde,

$4.21-5.00=$ Çok iyi düzeyde şeklindedir. 


\section{- Uygulama}

Taslak ölçek, Marmara bölgesindeki bir üniversitenin İngilizce hazırlık biriminde 93'ü kadın ve 102'si erkek olmak üzere toplamda 195 kişiye uygulanmıştır. Araştırmacının katılımcıları hazırlık birimindeki öğrencilerin tamamından oluşmaktadır.

\section{Bulgular}

Taslak ölçeğin uygulama aşamasından sonra ilk olarak madde analizleri yapılmış daha sonra yap1 geçerliğinin test edilmesi amacıyla açımlayıcı faktör analizi gerçekleştirilmiştir. Son olarak ölçeğin toplam ve faktörlerine ilişkin güvenirliğine yer verilmiştir. Bu basamaklar aşağıda yer almaktadır.

\section{Madde analizleri}

Ölçeğin yapı geçerliğini test etmek için öncelikle elde edilen veriler üzerinde madde analizleri yapılmıştır. Tablo 2'de görüldüğü gibi ölçek maddelerinin madde toplam korelasyonlarına bakılarak ,30'un altında değere sahip olan $(5,13,14,27,28,30,36)$ maddeler ölçekten çıkarılmıştır.

Tablo 2: YDDKÖ Madde Toplam Korelasyonları

\begin{tabular}{lll}
\hline Madde No & Madde Toplam Korelasyonlar & Madde Silindiğinde Cronbach Alpha \\
\hline Madde 1 & .56 & .88 \\
\hline Madde 2 & .57 & .88 \\
\hline Madde 3 & .50 & .88 \\
\hline Madde 4 & .51 & .88 \\
\hline Madde 5 & .29 & .89 \\
\hline Madde 6 & .52 & .88 \\
\hline Madde 7 & .32 & .89 \\
\hline Madde 8 & .47 & .88 \\
\hline Madde 9 & .38 & .89 \\
\hline Madde 10 & .51 & .88 \\
\hline Madde 11 & .50 & .88 \\
\hline Madde 12 & .49 & .88 \\
\hline Madde 13 & .26 & .89 \\
\hline Madde 14 & .16 & .89 \\
\hline Madde 15 & .39 & .89 \\
\hline Madde 16 & .54 & .88 \\
\hline Madde 17 & .41 & .89 \\
\hline Madde 18 & .63 & .88 \\
\hline Madde 19 & .47 & .88 \\
\hline Madde 20 & .49 & .88 \\
\hline Madde 21 & .69 & .88 \\
\hline Madde 22 & .58 & .88 \\
\hline Madde 23 & .61 & \\
\hline & & \\
\hline
\end{tabular}


Tablo 2: YDDKÖ Madde Toplam Korelasyonları (Devam)

\begin{tabular}{lcc}
\hline Madde No & Madde Toplam Korelasyonlarl & Madde Silindiğinde Cronbach Alpha \\
\hline Madde 24 & .50 & .88 \\
\hline Madde 25 & .37 & .89 \\
\hline Madde 26 & .44 & .88 \\
\hline Madde 27 & -.05 & .89 \\
\hline Madde 28 & .23 & .89 \\
\hline Madde 29 & .52 & .88 \\
\hline Madde 30 & .11 & .89 \\
\hline Madde 31 & .32 & .89 \\
\hline Madde 32 & .60 & .88 \\
\hline Madde 33 & .30 & .89 \\
\hline Madde 34 & 52 & .88 \\
\hline Madde 35 & 44 & .88 \\
\hline Madde 36 & -.26 & .90
\end{tabular}

\section{Yapı geçerliği}

Madde-toplam puan korelasyonu analizinden sonra ölçeğin yapı geçerliğinin belirlenmesi için açımlayıcı faktör analizi yapılmıştır. Kaiser Meyer Olkin ve Bartlett küresellik testleri sonucu $(\mathrm{KMO}=.89$ ve $\chi 2=1156.87, \mathrm{df}=153, \mathrm{p}<0.001)$ faktör analizinin uygunluğuna karar verilmiştir. Ölçek teorik açıdan da çok boyutlu görüldüğünden Varimax dik döndürme tekniği kullanılarak analiz birkaç kez tekrarlanmıştır. Yapılan analizler sonucunda 30 maddeden faktör yükü .30 'ın altında kalan, birden fazla faktöre yükleme yapan 10 madde $(3,4,6,19,20,21,26,31,32,35)$ ölçekten çıkarılmıştır. Ölçeğin yapı geçerliğine ilişkin faktör analizi sonuçları Tablo 3'te gösterilmektedir.

Tablo 3: YDDKÖ'nin faktör yapısı

\begin{tabular}{llll}
\hline Varyans : \% 49.2 & 1.Faktör & 2.Faktör & 3.Faktör \\
\hline M2 & .783 & & \\
\hline M1 & .771 & & \\
\hline M22 & .703 & & \\
\hline M18 & .701 & & \\
\hline M23 & .696 & & \\
\hline M24 & .685 & & \\
\hline M17 & & .668 & \\
\hline M8 & .645 & \\
\hline M10 & .638 & .808 \\
\hline M7 & .624 & .697 \\
\hline M9 & .582 & .654 \\
\hline M15 & .548 & .494 \\
\hline M16 & .492 & .371 \\
\hline M12 & & \\
\hline M11 & & \\
\hline M29 & & \\
\hline M34 & & \\
\hline M33 & & \\
\hline
\end{tabular}


Tabloda 3.'te görüldüğü üzere, yapılan analizler sonucunda kalan 18 maddenin 3 faktöre dağıldığı ve faktörlerin toplam varyansın \%49.2'sini açıkladığı saptanmıştır. Birinci faktör ölçeğe ilişkin toplam varyansın \% 18.3'ünü, ikinci faktör \% 17'sini, üçüncü faktör \% 13.9'unu açıklamaktadır. Ayrıca, ölçekte 1 ters madde bulunmaktadır. Maddelerin faktör yüklerinin .372 ile .808 arasında değiştiği saptanmıştır. Ayrıca faktörlerin öz değerleri 1.329 ile 5.898 arasında değişmektedir. Öz-değeri 1 ve 1 'in üzerinde olan faktörler önemli kabul edilmektedir. Bu sonuçlar ölçeğin yeterli düzeyde geçerliğe sahip olduğu göstermektedir.

\section{Güvenirlik}

Ölçeğin güvenirliği iç tutarlık yöntemi ile incelenmiştir. Ölçeğin faktörlerinin Cronbach Alpha katsayıları hesaplanmıştır. Ölçeğin faktörlerine ilişkin Cronbach Alpha değerleri Tablo 4.'te gösterilmektedir.

Tablo 4: Yabancı Dil Katılım Ölçeğinin Faktörlerine İlişkin Cronbach Alpha Değerleri

\begin{tabular}{lll}
\hline Faktörler & Madde Sayıs & Cronbach Alpha \\
\hline 1- Faktör & 6 & .83 \\
\hline 2- Faktör & 7 & .76 \\
\hline 3- Faktör & 5 & .63 \\
\hline Toplam & 18 & .86 \\
\hline
\end{tabular}

$* \mathrm{n}=195$

Tabloda görüldüğü üzere ölçeğin Cronbach Alpha toplam iç tutarlık kat sayısı faktörlerde .63 ile .83 arasında değerler alırken, ölçeğin geneli için ,86 olduğu saptanmıştır. Bu sonuçlar, ölçeğin yeterli düzeyde bir güvenirliğe sahip olduğunu göstermektedir. Ölçeğin faktörleri arasındaki korelasyon analizi sonuçları Tablo 5 'te gösterilmektedir.

Tablo 5: Yabancı Dil Dersi Katılım Ölçeği Faktörleri Arasındaki Korelasyon Analizi Sonuçları

\begin{tabular}{lcccc}
\hline Faktörler & & Duyuşsal Katılım & Bilişsel Katılım & Sosyal Katılım \\
\hline Duyuşsal Katılım & $\mathrm{r}$ & 1 & $.53^{* *}$ & $.50^{* * *}$ \\
\cline { 2 - 5 } & $\mathrm{p}$ & & .00 & .00 \\
\hline Bilişsel Katılım & $\mathrm{r}$ & $.53^{* *}$ & 1 & $.37^{* *}$ \\
\cline { 2 - 5 } & $\mathrm{p}$ & .00 & $.37^{* *}$ & .00 \\
\hline Sosyal Katılım & $\mathrm{r}$ & $.50^{* *}$ & .00 & 1 \\
\cline { 2 - 5 } & $\mathrm{p}$ & .00 & &
\end{tabular}

** $\mathrm{p}<.01, \eta=195$

Yabancı Dil Dersi Katılım Ölçeği’nin duyuşsal katılım, bilişsel katılım ve sosyal katılım faktörleri arasındaki ilişkiler Pearson korelasyon analiziyle hesaplanmış̧ır. Duyuşsal katılım faktörünün bilişsel katılım faktörüyle $r=.537 ; \mathrm{p}<.01$; sosyal katılım faktörüyle $r=.503 \mathrm{p}<.01$ düzeylerde; bilişsel katılım faktörünün, sosyal katılım faktörüyle $r=.377 ; \mathrm{p}<.01$ düzeylerde pozitif yönde ve istatistiksel olarak anlamlı ilişkisi saptanmıştır.

Ölçek maddelerinin isimlendirilmesinde Svalberg'in (2009: 247) yabancı dil dersinde katılım kavramı için öne attığı boyutlar temel alınmıştır. Buna göre birinci faktör duyuşsal katılım, ikinci faktör bilişsel katılım ve üçüncü faktör ise sosyal katılım olarak adlandırılmıştır. Yabancı dil dersi katılım ölçeği maddeleri Tablo 6'da yer almaktadır. 
Tablo 6: Yabancı Dil Dersi Katılım Ölçeği Maddeleri

\begin{tabular}{|c|c|c|c|}
\hline Maddeler & \begin{tabular}{|l} 
Duyuşsal \\
Katılım
\end{tabular} & $\begin{array}{l}\text { Bilişsel } \\
\text { Katılım }\end{array}$ & $\begin{array}{l}\text { Sosyal } \\
\text { Katılım }\end{array}$ \\
\hline M1. İngilizce dersinde kendimi öğrenmeye hazır hissederim. & .801 & & \\
\hline M2. İngilizce dersinde kendimi enerjik hissederim. & .785 & & \\
\hline M22. İngilizce dersinde kendimi iyi hissederim. & .703 & & \\
\hline M18. İngilizce dersine katılmaya istekliyimdir. & .677 & & \\
\hline 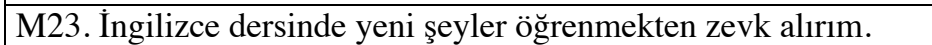 & .546 & & \\
\hline M24. İngilizce dersinde ilerleme kaydettiğimi düşünnüyorum. & .508 & & \\
\hline $\begin{array}{l}\text { M17. İngilizce dersinde yeni bir şey öğrenirken konuyu kendi } \\
\text { cümlelerimle ifade ederim. }\end{array}$ & & .668 & \\
\hline $\begin{array}{l}\text { M8. İngilizce dersinde geliştirilmesi gereken yanlarımı fark } \\
\text { ederim. }\end{array}$ & & .645 & \\
\hline $\begin{array}{l}\text { M10. İngilizce dersinde öğrendiklerimi önceki öğrenmelerimle } \\
\text { ilişkilendiririm. }\end{array}$ & & .638 & \\
\hline $\begin{array}{l}\text { M7. İngilizce dersinde dil yapılarını inceleyerek kuralları kendim } \\
\text { çıkarırım. }\end{array}$ & & .624 & \\
\hline $\begin{array}{l}\text { M9. İngilizce dersindeki performansımın nasıl olduğunu } \\
\text { değerlendiririm. }\end{array}$ & & .582 & \\
\hline $\begin{array}{l}\text { M15. İngilizce dersinde arkadaşlarıma konuyla ilgili sorular } \\
\text { sorarım. }\end{array}$ & & .548 & \\
\hline $\begin{array}{l}\text { M16. İngilizce dersinde öğrendiklerimi gerçek yaşamda nasıl } \\
\text { kullanabileceğimi düşünürüm. }\end{array}$ & & .492 & \\
\hline $\begin{array}{l}\text { M11. İngilizce dersinde zorlandığım yerlerde öğretmenimden } \\
\text { yardım isterim. }\end{array}$ & & & .808 \\
\hline $\begin{array}{l}\text { M12. İngilizce dersinde konuyla ilgili öğretmenime sorular } \\
\text { sorarım. }\end{array}$ & & & .697 \\
\hline $\begin{array}{l}\text { M29. İngilizceyi daha iyi öğrenmek için arkadaşlarımla iletişim } \\
\text { kurarım. }\end{array}$ & & & .654 \\
\hline M33. Derste bana bir şey sorulmadığı sürece sessiz kalırım. & & & .494 \\
\hline M34. Ders hakkındaki önerilerimi dile getiririm. & & & .371 \\
\hline
\end{tabular}

\section{Tartışma ve Sonuç}

Katılım, sınıf ortamında yabancı dil öğretiminin dinamiklerini araştırmada önemli bir değişken olarak karşımıza çıkmaktadır (Oga-Baldwin ve Nakata, (2017: 151). Yabancı dil öğretimiyle ilgili literatürde katılım kavramının farklı boyutları ele alınmış olmasına rağmen bu kavram ampirik çalışmalarda genellikle tek bir boyutta ele alınmıştır. Katılım kavramını yabancı dil dersi bağlamında ele alan bu araştırmada, katılımın bilişsel, sosyal ve duyuşsal yönüne vurgu yapılarak dil edinimi teorik çerçevesi ve dil öğrenme hedef-süreçleri temel alınmıştır. Bu çalışmada İngilizce dersinde öğrenci katılımının belirlenmesinde kullanılabilecek geçerli ve güvenilir bir ölçme aracı geliştirilmiştir. Bu amaçla, ilk olarak kavramın teorik çerçevesini belirlemek amacıyla literatür taraması yapılmış ve Svalberg (2009:244) tarafından tanımlanan ve dil öğrenme sürecinde öğrenci katılımını ifade eden yabanc1 dil dersinde katılım (engagement with language) kavramı benimsenmiştir. Madde havuzunun belirlenmesinde yabancı dil dersinde katılım kavramının boyutlarına ilişkin olarak belirlenen katılım kriterlerinden yararlanılmıştır. Taslak ölçek için sosyal, bilişsel ve duyuşsal boyutlarda belirlenen bu kriterler kullanılarak 44 madde yazılmıştır. Taslak ölçeğin kapsam geçerliliği Lawshe'nin CVR yöntemiyle gerçekleştirilmiş ve 8 madde ölçekten çıkarılmıştır. 36 maddeli ve 5'li likert yapıda olan taslak ölçek Marmara bölgesindeki bir üniversitenin İngilizce hazırlık biriminde 93'ü kadın ve 102'si erkek olmak üzere toplamda 195 kişiye uygulanmıştır. 
Taslak ölçeğin uygulandığı pilot çalışmadan sonra öncelikle madde toplam korelasyon analizi yapılmış ve 8 madde daha ölçekten çıkarılmıştır. Bu analizden sonra ölçeğin yapı geçerliliği belirlemek üzere varimax yöntemiyle faktör analizi yapılmıştır. Açımlayıcı faktör analizi sonucunda faktör yükü .30'ın altında kalan, birden fazla faktöre yükleme yapan 10 madde ölçekten çıkarılmıştır. Yapılan analizler sonucunda kalan 18 maddenin 3 faktöre dağıldı \%49,2'sini açıkladığı saptanmıştır. Birinci faktör ölçeğe ilişkin toplam varyansın \% 18,3'ünü, ikinci faktör \% 17'sini, üçüncü faktör \% 13,9'unu açıklamaktadır. Maddelerin faktör yüklerinin ,372 ile ,808 arasında değiştiği saptanmıştır. Ayrıca faktörlerin öz değerleri 1,329 ile 5,898 arasında değişmektedir. Ayrıca, ölçekte 1 ters madde bulunmaktadır. Bu sonuçlar ölçeğin yeterli düzeyde geçerlik ve güvenirliğe sahip olduğu göstermektedir.

Ölçeğin güvenirliği ise iç tutarlık yöntemi ile incelenmiştir. Ölçeğin faktörlerinin Cronbach Alpha katsayıları hesaplanmış ve Cronbach Alpha iç tutarlık kat sayısı faktörlerde ,63 ile ,83 arasında değerler alırken, ölçeğin geneli için ,86 olduğu saptanmıştır. Bu sonuçlar, ölçeğin yeterli düzeyde bir güvenirliğe sahip olduğunu göstermektedir. Ayrıca, ölçeğin faktörleri arasındaki anlamlı ve pozitif yöndeki ilişkiler ölçeğin güvenilir bir ölçek olduğunu desteklemektedir. Yabancı Dil Dersi Katılım Ölçeği'nin boyutlarının duyuşsal katılım, bilişsel katılım ve sosyal katılım olarak isimlendirilmesinde Svalberg'in (2009: 247) yabancı dil dersinde katılım kavramı için öne attığ boyutlar temel alınmıştır. Buna göre birinci faktör duyuşsal katılım, ikinci faktör bilişsel katılım ve üçüncü faktör ise sosyal katılım olarak adlandırılmıştır. Yabancı Dil Dersi Katılım Ölçeği'nin farklı örneklemlerde ve kültürlerde güvenirlik ve geçerlilik çalışmasının yapılması önerilebilir. Bu anlamda farklı yabancı dillerin öğrenildiği sınıf ortamları incelenebilir. İleriki araştırmalarda yabancı dil dersinde katılımın sınıf ortamında demografik değişkenler açısından nasıl farklılaştığı, öncülleri ve sonuçları araştırılabilir.

\section{Kaynakça}

Anderson, A. R., Christenson, S. L., Sinclair, M. F., \& Lehr, C. A. (2004). Check \& connect: The importance of relationships for promoting engagement with school." Journal of School Psychology, 42(2), 95-113. https://doi.org/10.1016/j.jsp.2004.01.002

Appleton, J. J., Christenson, S. L., Kim, D., \& Reschly, A. L. (2006). Measuring cognitive and psychological engagement: Validation of the student engagement instrument. Journal of School Psychology, 44(5): 427-445. https://doi.org/10.1016/j.jsp.2006.04.002

Asghar, H. M. 2014. Patterns of engagement and anxiety in university students. Students work engagement and anxiety: Are they related? Pracana, C. (Ed), Psychology Applications \& Development içinde. Portugal: Science Press.

Astin A. (1984) Student involvement: a developmental theory for higher education. Journal of College Student Personnel." 25: 297-308.

Baralt, M., Gurzynski-Weiss, L., \& Kim, Y-J. (2016). Engagement with the language. How examining learners' affective and social engagement explains successful learner-generated attention to form. In M. Sato \& S. Ballinger (Eds.), Peer interaction and second language learning: Pedagogicalpotential and research agenda içinde (pp. 209-240). Amsterdam/Philadelphia: John Benjamins. https://doi.org/10.1075/11lt.45.09bar

Ellis, R. (2009). Task-based language teaching: Sorting out the misunderstandings. International Journal of Applied Linguistics, 19(3): 221-246. https://doi.org/10.1111/j.14734192.2009.00231.x

Ellis, R. (2010). A Framework for investigating oral and written corrective feedback. Studies in Second Language Acquisition, 32: 335-349. https://doi.org/10.1017/s0272263109990544 
Eren, A. (2013). Prospective teachers' perceptions of instrumentality, boredom coping strategies, \& four aspects of engagement. Teaching Education, 24(3): 302-326. https://doi.org/10.1080/10476210.2012.724053

Eryılmaz, A. (2014). Üniversite öğrencileri için derse katılım ölçeklerinin geliştirilmesi. Uşak Üniversitesi Sosyal Bilimler Dergisi, 7(2): 203-214. https://doi.org/10.12780/uusbd356

Finn, J., \& Cox, D. (1992). Participation and withdrawal among 4th-grade pupils. American Educational Research Journal, 29(1): 141-162. https://doi.org/10.3102/00028312029001141

Fredericks, J. A., Blumenfeld, P. C., \& Paris, A. H. (2004). School engagement: Potential of the concept, state of the evidence. Review of Educational Research, 74: 59- 109. https://doi.org/10.3102/00346543074001059

Fredricks, J. A., \& McColskey, W. (2012). The measurement of student engagement: A comparative analysis of various methods and student self-report instruments. In S. L. Christenson, A. L. Reschly, \& C. Wylie (Eds.), Handbook of research on student engagement (pp. 763-782). New York, NY, US: Springer Science + Business Media. https://doi.org/10.1007/978-14614-2018-7 37

Günüç, S., \& Kuzu, A. (2015) Student engagement scale: development, reliability and validity. Assessment \& Evaluation in Higher Education, 40(4): 587-610. https://doi.org/10.1080/02602938.2014.938019

Gürer, D. G. (2013). Sosyal bilgiler dersinde öğrenme nesnelerinin kullanımı: Başarı, tutum ve derse katılim [Utilization of learning objects in social studies lesson: Achievement, attitude and engagement]. Yayınlanmamış doktora tezi. Orta Doğu Teknik Üniversitesi, Fen Bilimleri Enstitüsü, Ankara.

Güvenç, H. (2015). Etkin katılım ölçeği geliştirme ve uyarlama çalışması. Journal of Kirsehir Education Faculty, 16(1): 255-267.

Handelsman, M., Briggs, W., Sullivan, N., \& Towler, A. (2005). A measure of college student course engagement. Journal of Educational Research, $98 \quad$ (3):184-191. https://doi.org/10.3200/joer.98.3.184-192

Hıdıroğlu, F.M. (2014). The Role of Perceived Classroom Goal Structures, Self-efficacy, and the Student Engagement in Seventh Grade Students' Science Achievement. Yüksek lisans tezi, Orta Doğu Teknik Üniversitesi, Ankara.

Kuh G.D. (2009) What student affairs professionals need to know about student engagement. Journal of College Student Development 50: 683-706. https://doi.org/10.1353/csd.0.0099

Marks, H. M. (2000). Student engagement in instructional activity: patterns in the elementary, middle, and high school years. American Educational Research Journal, 37(1):153-184. https://doi.org/10.3102/00028312037001153

Newmann, F. M., Wehlage, G. G., \& Lamborn, S. D. (1992). The significance and sources of student engagement. In F. M. Newmann (Ed.), Student engagement and achievement in American secondary schools (pp. 11-39). New York: Teachers College Press.

Oga-Baldwin, W. Q., \& Nakata, Y. (2017). Engagement, gender, and motivation: A predictive model for Japanese young language learners. System, 65: 151-163. doi:10.1016/j.system.2017.01.011 https://doi.org/10.1016/j.system.2017.01.011

Philp, J., \& Duchesne, S. (2016). Exploring engagement in tasks in the language classroom. Annual Review of Applied Linguistics, 36: 50-72. https://doi.org/10.1017/s0267190515000094 
Reeve, J. (2013). How students create motivationally supportive learning environments for themselves: The concept of agentic engagement. Journal of Educational Psychology, 105: 579-595. https://doi.org/10.1037/a0032690

Reeve, J., \& Tseng, C. (2011). Agency as a fourth aspect of students' engagement during learning activities. Contemporary Educational Psychology, 36( 4): 257-267. https://doi.org/10.1016/j.cedpsych.2011.05.002

Skinner, E. A., Kindermann, T. A., \& Furrer, C. J. (2009). A Motivational Perspective on Engagement and Disaffection: Conceptualization and Assessment of Children's Behavioral and Emotional Participation in Academic Activities in the Classroom. Educational and Psychological Measurement, 69: 493-525. https://doi.org/10.1177/0013164408323233

Stroud, R. (2017). The impact of task performance scoring and tracking on second language engagement. System, 69: 121-132. https://doi.org/10.1016/j.system.2017.07.002

Svalberg, A. M.-L. (2009) Engagement with language: interrogating a construct. Language Awareness, 18(3-4): 242-258, https://doi.org/10.1080/09658410903197264

Svalberg, A. M.-L. (2017). Researching language engagement; current trends and future directions. Language Awareness, 27(1-2): 21-39. https://doi.org/10.1080/09658416.2017.1406490 